\title{
An Industrial Robotics Course Based on a Graphical Simulation Package
}

\author{
Manuel F. Silva \\ ISEP/IPP - School of Engineering, Polytechnic Institute of Porto \\ INESC TEC - INESC Technology and Science (formerly INESC Porto) \\ Porto, Portugal \\ mss@isep.ipp.pt
}

\begin{abstract}
In recent years there has been an increasing introduction of industrial robots in the manufacturing industry, with several studies that predict the increased dissemination of robots in industrial and service sectors. On the other hand, there is often the lack of people able to plan the introduction of these equipments in manufacturing environments and to operate it after its inception. This leads to the need to train undergraduates in the operation and programming of industrial robots. Due to the Portuguese economic situation, there is a lack of funding for the higher schools, leading to the need of finding innovative ways to teach these subjects. Bearing in mind these ideas, in this paper is described a course on industrial robotics, which is based in the achievement of the practical training using commercial off-theshelf robot simulation software for off-line programming.
\end{abstract}

Keywords-robotics; education; simulation; off-line programming

\section{INTRODUCTION}

Recent years have witnessed an increasing introduction of robots in industry (and to a lesser extent in services), with several studies predicting the increased dissemination of robots in industrial and service sectors [1-3]. This is mainly due to advances in factory automation, particularly in small and medium volume production factories, that require high flexibility in production equipment, a role that robots can play. On the other hand, there is in Portugal a lack of people able to plan the introduction of this equipment in manufacturing environments and to operate it after its inception. This environment requests for courses on industrial robotics that are able to train people on the design of robotic work cells and on the programming and operation of these devices [4].

Realizing these facts, in 2006, when the Portuguese High School system had to adapt to the Bologna Agreement [5], it was decided to offer an optional course on industrial robotics (named ROBIN - Robótica Industrial) to the students of the Master Course on Electrical and Computer Engineering (Mestrado em Engenharia Electrotécnica e de Computadores MEEC), offered at the School of Engineering of the Polytechnic Institute of Porto (Instituto Superior de Engenharia do Porto - ISEP). This Master Course is organized into four specialization areas, namely Automation and Systems (Automação e Sistemas - AS), Autonomous Systems (Sistemas
Autónomos - SA), Telecommunications (Telecomunicações $\mathrm{T}$ ) and Industrial Planning and Systems (Sistemas e Planeamento Industrial - SPI), and the ROBIN course was mainly foreseen to the offered to the students of the AS specialization area.

This course presents as its main objectives to teach the principles of robotic manipulation and its key application fields. The aspects of mathematical foundation of robotics are placed in a background, being referred just in an introductory phase of the course. In this way, it is intended to make the students aware of the terminology used in robotics and create in them a knowledge base that allows them to identify which applications may be subject of robotization, bearing always in mind the advantages and limitations of robots utilization. It is still the objective of this course to supply tools for the development of robotic applications (including the study of robot operation and programming) and focus on the main aspects of safety regulations to be followed in the development of these applications. It should be mentioned that, although it is not studied a particular robot programming language, it is expected that at the end of this course students (that acquired programming skills in other courses of their undergraduate studies) will be able to easily learn and understand any programming language to program robot manipulators.

According to the transposition of the Bologna Agreement to the Portuguese Legislation, the ROBIN course should have 20 weeks of duration (of which four weeks are used for evaluation purposes) and six European Credit Transfer Units (ECTU) were attributed to it internally while designing the MEEC. For this given number of ECTU, the weekly organization of the course comprises two hours of theoretical lectures, one hour for monitoring students' work and two hours of hands-on laboratory practice, corresponding the rest of the workload to work activities that the students have to develop outside of the classroom.

Although being an optional course mainly intended for the students of the MEEC-AS specialization area, this course has been active in the Autumn semesters for all academic years since its inception in the academic year of 2007/2008. In this academic year the course has enrolled students from the specialization areas of AS, SA, SPI and also from two other master courses offered at ISEP, the Master Course on 
Instrumentation and Medical Computing (Mestrado em Computação e Instrumentação Médica - MCIM) and the Master Course on Instrumentation and Metrology Engineering (Mestrado em Engenharia da Instrumentação e Metrologia MEIM). The pedagogical inquires made to the students after the course completion have been giving positive feedback concerning the organization and the functioning of the course.

Keeping these ideas in mind, the sequel of this paper is organized as follows. Section two presents a brief state of the art concerning robotics education. Section three presents the organization of the ROBIN course. Based on the experience of teaching this course for the last six academic years, section four presents some results gathered from this experience and section five a discussion on the course implementation. Finally, on section six are presented the main conclusions of this paper.

\section{StATE OF THE ART IN RobOtics EdUCATION}

Considering the increasing introduction of robots in industry and in services, and the above identified need to teach robotics courses and carry out research related to robotics field, several courses in High Schools and Universities around the world are offered on mobile robots [6-10].

In order to disseminate robotics education, some Internet based remote laboratories have been implemented for teaching robotics, such as the UJI Tele-Lab [11], the Virtual Laboratory for the education in Robotics and Automation at the Universitá di Verona [12], the Tele-robotics system in the BILTIR CAD/CAM Robotics Center of the Middle East Technical University [13], the TIGER - Telepresence Instant Groupware for Higher Education in Robotics project [14], the Automatic Control Telelab of the Universitá di Siena [15], the Open laboratory of the Department of Automatic Control and Computer Engineering at the Universitat Politècnica de Catalunya [16], and the GigaBOT Web Lab for mobile robotics education [17]. Finally, several institutions made available through the internet sites were the user can interact with real robots, either with educational purposes or just for fun $[18,19]$.

Besides using the internet to disseminate teaching and education, without the inherent costs of hardware, another possibility is the use of simulation applications. There are documented uses of simulation software packages for teaching robotics, such as the use of Simulink SimMechanics for the modelling and simulation of a robot arm, controller design, and controller implementation [20] and its use for solving the poses and active forces of parallel manipulators [21], the use of graphical simulators for the learning of kinematic and dynamic aspects of robotics [12], and the use of the open source robot simulator USARSim both for research and education [22].

From the above description of the revised literature, it can be concluded that courses on industrial robotics are not frequently presented. Little information has been found on the use of commercial off-the-shelf simulation software packages for offline programming used to support the teaching of industrial robotics programming and operation, although software simulation applications are used in teaching several distinct subjects [23]. An exception is the work by Rawat and Massiha, developed at the Department of Industrial Technology at the University of Louisiana at Lafayette [24].
These authors describe their teaching experience, gathered along four years, including the choices of robotics platform, simulator, typical experiments and projects they have conducted for students. In order to offer hands-on experience in operating the robots and design of manufacturing works cells, a fully-equipped robotics laboratory has been established, equipped with ten bench top educational robotic systems interfaced with PCs. The software used is SCORBASE and ROBOCELL. Particularly, SCORBASE robotic software provides a graphic display module, which allows students to teach robot positions and execute robot programs in a virtual robotic cell, therefore realizing the robot off-line programming.

It also deserves a mention the Virtual CIM Laboratory (VCIMLAB), developed at the Eastern Mediterranean University (Turkey) for laboratory training on Computer Integrated Manufacturing (CIM) systems [25]. The VCIMLAB allows students to self-experience on automated manufacturing systems (including industrial robots) without the need to work on actual equipment in the laboratory.

As presented in the next section, the approach followed in the implementation of the ROBIN course is also based on a simulation software package and an industrial robot. This way, with low cost, it is possible to have all students learning robot operation and programming and seeing the results of their programming actions is real time. The programs developed offline, which work properly in simulation, are downloaded to the real robot, where the students have to operate this equipment while testing the programs on-line.

\section{ORgAniZATION OF THE COURSE}

This section describes the course organization. It starts with a description of the course objectives, followed by the program that was prepared for the course in order to achieve the stated objectives. Next is described the organization of the classes and are referred the specific subjects of the course program that are taught in each type of classes, giving some emphasis on the laboratory classes were the simulation software is used for teaching robot operation and programming.

\section{A. Characterization of the Course Objectives}

Before developing the course program, its objectives were characterized and were classified according to the European Accreditation of Engineering Programmes (EUR-ACE) requirements [26, 27], as follows:

1) Knowledge and Understanding: This first axis regards the knowledge and understanding level that the students should acquire, concerning the main topics on industrial robots. Regarding this axis, after the students conclude this course with success they should know and understand what are the key characteristics of industrial robots. They should be able to read the data sheets of industrial robots and be able to understand the key features listed herein. They should also have knowledge of the main types of end-effectors available in the market for industrial robots and understand what are the principles of operation of each one of these end-effectors and their potential applications. Finally, the students should also 
know the basic security legislation that applies to the design, installation and operation of industrial robots and understand the implications in terms of health and safety of the use of industrial robots without the due consideration of the applicable legislation.

2) Research: Concerning this axis, one of the course objectives is to foster and train in the students the capability to research solutions to problems in a self-oriented or autonomous manner. They should be able to find information on topics related to the design of robotic work cells and programming and operation of robots in an autonomous way.

3) Engineering Analysis, Project and Practice: It is also one of the course objectives that the students develop their ability to analyse the requirements for the industrial applications of robots, to design applications of industrial robots in work contexts and that they are capable to develop programs for industrial robots.

4) Surrounding Context: Concerning this axis, it is the course objective to develop the students soft skills. This is mainly achieved through the development of teamwork skills and of personal and interpersonal skills. It is also an objective to foster the students skills to communicate their conclusions and the knowledge and reasoning underlying them, to either specialists or non-specialists, in a clear and unambiguous way.

\section{B. Program of the Course}

The program of the course is briefly outlined below. This program was developed in order to achieve the first course objective, presented in the previous subsection. These subjects are mainly to be taught in the theoretical classes of the course, except for point 4. that is thoroughly addressed in the laboratory classes:

1. Introduction to robotics
a. Origin of the terminology
b. Historical evolution
c. Problems associated with the industrial use of robotic systems
d. Key features

2. Basic notions of robotics
a. Basic terminology of industrial robots
b. Main configurations of industrial robots
c. Workspace
d. Methods of actuation of industrial robots
e. Motion control systems
f. Direct and inverse kinematics
g. Direct and inverse dynamics
h. Trajectory planning and control

3. Grippers and tools for industrial robots
a. Grippers
b. Tools for mechanical operations
c. Tools for welding
d. Coaxial insertion units

e. Systems for the automatic exchange of grippers/tools

f. Factors to consider in the design and selection of robot end effectors

4. Robot programming methods and their evolution

a. Industrial robots programming languages

b. Online programming

c. Off-line programming

d. Off-line programming of robots using simulation software

5. Safety during robot programming and operation
a. Dangers of robots
b. Passive protection measures
c. Active protection measures
d. Human-robot interfaces in robotic cells
e. Tool changes

6. Industrial applications of robotics
a. Handling and palletizing of materials
b. Processing operations
c. Assembly operations

7. Methodologies for the implementation of robotic applications
a. Planning of the application
b. System development
c. Tests with the cell
d. Installation
e. Starting and monitoring

8. New robotic application areas
a. New applications of industrial robotics
b. Applications of robotics to services.

\section{Organization of the Classes}

The course on industrial robotics has a planned duration of 16 weeks of classes, with 5 hours of classes each week. The five weekly hours of lectures are distributed in two theoretical lectures, with the duration of one hour each, one tutorial lecture with a duration of one hour, and one laboratory class with a duration of two hours.

In order to achieve the course objectives, the classes are organized in such a way that in the theoretical classes are presented the theoretical subjects by the teacher, mainly using the expository method, supported by Power Point slides. The lectures are accompanied by the presentation of small commercial videos of robotic technologies and applications.

In the tutorial classes it is given the needed support to the development of a research work developed by groups of three/four students. The research works deal with finding the solutions to applications of industrial robots in practical industrial applications. This group work is the subject of a public presentation and discussion, in order to foster the course objective described above in item 4). 


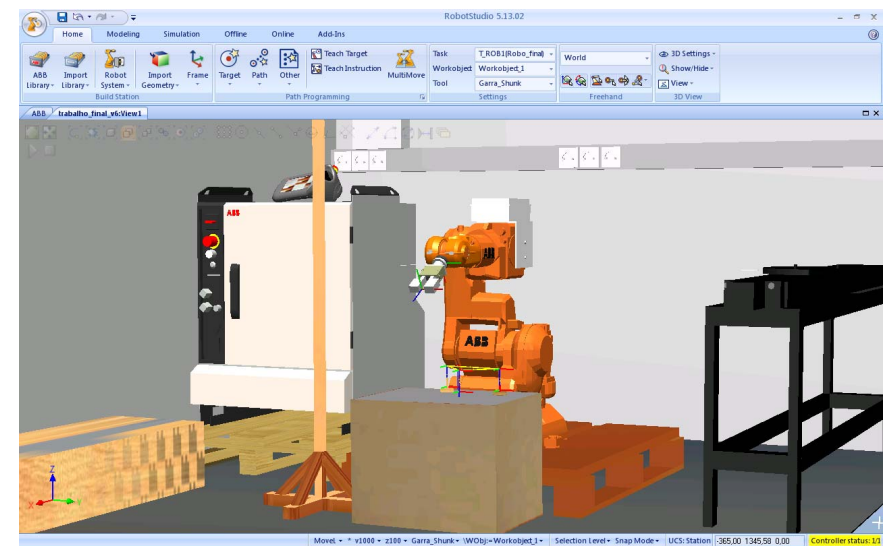

Fig. 1. Model of the robot cell, used to develop the robot program in offline mode, developed in the simulation software package.

Finally, in the laboratory classes the objective is to teach students the principles of robot programming. What is usually found is that many students are mainly interested in solving practical problems, whereas the lecturer usually aims at teaching profound knowledge of the analysis and applications of robotic systems. This gap between the application-oriented expectation of the learner and the theory focused material chosen by the lecturer may end up in a considerable demotivation of the students, which in turn lowers their learning performance. In order to overcome this problem, these classes are organized according to a hands-on project based approach.

To implement this methodology, the laboratory classes are divided in two periods. In the first period, corresponding to the first five weeks of classes, the students learn (in an autonomous way) the work principle of a robotic simulation and off-line programming software for industrial robots (namely ABB RobotStudio 5.15.02, from ABB Robotics) based on five laboratory works instruction scripts developed by the teacher. The laboratory works instruction scripts that are given to students cover the basic aspects of developing a program using ABB RobotStudio and are also intended to cover some basic aspects of industrial robots concepts and programming.

Concerning simulation and off-line programming tools, these help off-line programming robotic cells while the line is still running. With simulation packages, various scenarios may be simply tested by moving the object in question on a computer screen and retrying the simulation. During the offline programming process, it is possible to test programs for common trouble spots such as reach problems, collisions, joint limits, and cycle time. Once the user is satisfied with the simulation results, he instructs the simulation software to run the program.

After the students understand how ABB RobotStudio works, and the basics of robot programming, they have to develop, by their own, the simulation of a robotic cell, including the program for the robot that exists in this cell (an ABB IRB 140 manipulator). During this second period of laboratory classes the teacher mainly works as a tutor, directing the students on solving problems that they may face, but without a direct intervention in the work that is being developed by the students.

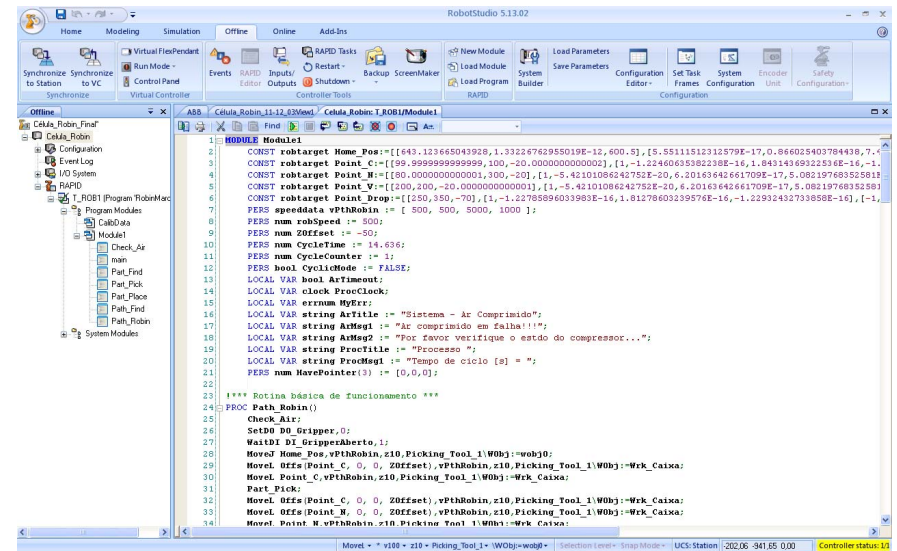

Fig. 2. Example of a robot program developed in ABB RobotStudio.

The educational software and hardware together emulate the manufacturing environment. These aid students to rapidly test and refine new behaviors before running them on the actual robotic system. This way, the resources in the laboratory are extensively used for conducing hands-on lab assignments.

The five instruction scripts, with a short description of the learning objectives of each, are described next.

1) Instructions Script 1 - Creation of the World Model: This script is intended to be an initial approach to the development of the model of a real workcell for an industrial robot in a simulation software package for the off-line programming of industrial robots. In this case, the robot to be used is the model IRB 140, from ABB Robotics. During the realization of this instruction script students get familiar with the tools supplied by ABB RobotStudio to build a geometrical model of workcells and the equipment herein, as can be seen in the example of Figure 1, that depicts the workcell at ISEP laboratory.

2) Instructions Script 2 - Targets Creation: It is intended, with this script, to supply to the students basic information on the establishment of targets to perform the off-line programming of industrial robots. While performing this instruction script students get familiar with the distinct types of targets that can be taught in robots, such as targets, joint targets and the different configurations (solutions of the inverse kinematics) that can be attributed to each target during the robot motion to that target.

3) Instructions Script 3 - Development of the Program: With this laboratory work instruction script, it is intended to give students basic information about the automatic operation of the robot. This instruction script drives students through the process of sequencing the movements of the robot, choosing between different types of motion interpolation (such as pointto-point, continuous, arc), as well as choosing the correct parameters for the robot motion (such as the speed of the movement, the approximation to the via points, etc.). In Figure 2 is presented an example of a program developed in this environmentby the students. 


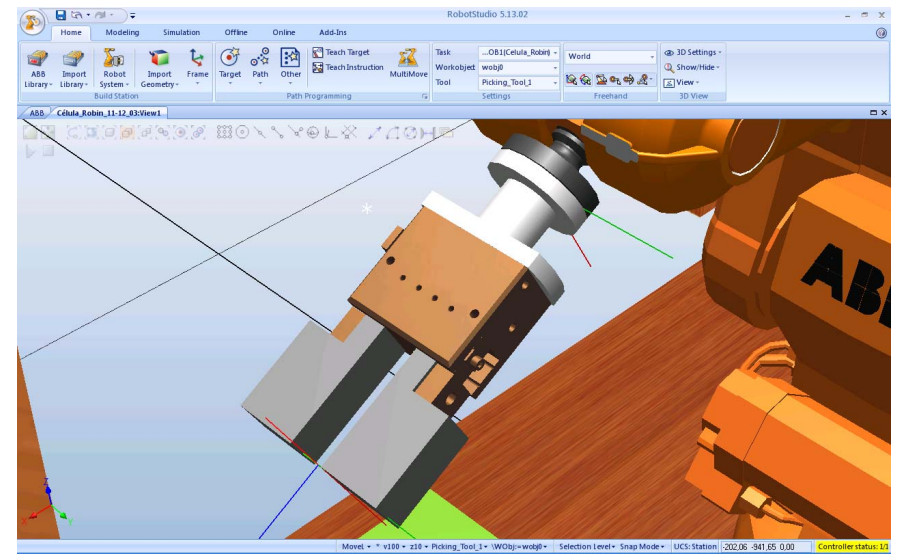

Fig. 3. Example of a mechanism (the robot gripper) developed in the simulation software package.

4) Instructions Script 4 - Simulation of the Robot Program in the Virtual Controller: This laboratory work instruction script supplements the basic programming and simulation of industrial robots, addressing aspects such as the downloading of the program to the virtual controller and the simulation of its execution. It also exposes some of the features of the ABB RobotStudio simulation toolbar. It is during the execution of this instruction script that students learn how to detect collisions between components of the work cell and the robot and its end-effector, compute cycle times, insert instructions for controlling I/Os in the robot program and simulate these signals.

5) Instructions Script 5 - Creation of a Mechanism: This laboratory work instruction script aims to give students the foundation for the creation of mechanisms, with proper motions, in ABB RobotStudio. During the realization of this instruction script students are guided in the modelling of a robot gripper (an example of which can be seen in Figure 3), and learn in a practical manner the distinctions between links (and the definition of base link), joints, axis of motion, and, most important, they have to define the tool centre point (TCP) of the modelled gripper.

As previously stated, the role of the teacher is different in the various phases of activity. At the beginning this role is active and passes mainly through the proposal of methodological guidelines for the development of the project and through an organized presentation of the tools to be used in the simulation and off-line programming. As soon as the students enter in the work cell simulation and robot off-line program development phase, the function of the tutor gradually passes to that of a reference person present in the work-group, ready to help in the solution of any problem, but purposely with no will to influence the choices of the designers, that are left free to move along the directions they prefer. The main effort of the tutor is to stimulate the creativity of the students suggesting a correct way to examine the problems and to formulate solutions, without conditioning their decisional process.

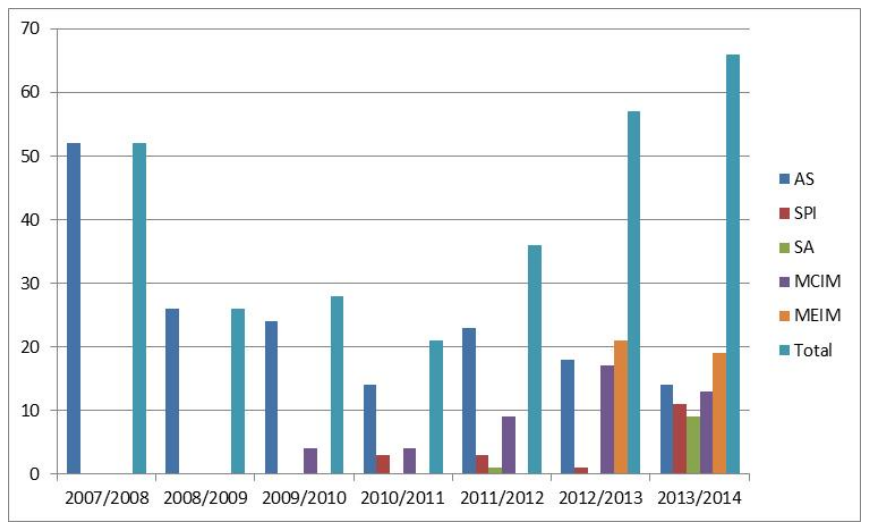

Fig. 4. Evolution of the number of enrolled students on the ROBIN course per academic year and their origin.

Maybe due to the fact that the students are fully motivated and that they are developing their ideas and representing them, the learning process has been extraordinarily fast and after a few weeks they are exhibiting full command of the robot simulation and off-line programming software package.

\section{COURSE IMPLEMENTATION RESULTS}

The Industrial Robotics course has presently run for six academic years. Figure 4 presents the evolution of the number of enrolled students per academic year. Its first edition was on the Autumn Semester of the academic year 2007/2008. In this first edition the course had 52 students enrolled (this peak in the number of students was due to the process of adaptation of the courses to the Bologna Agreement). In this edition, that is taking place on the Autumn Semester of the academic year of 2013/2014 there are 66 students enrolled. Furthermore, the course began by being chosen only by students from the Specialization Area of AS of the MEEC. However, in this last edition the students enrolled are from the Specialization Areas of AS, SPI and SA of the MEEC, from the MCIM and from the MEIM. These figures, per se, already give an indication of the success that this course is making among ISEP students.

Another indication of the course success is given by the results of the pedagogical inquires that are made to students at the final of each course. According to the results of these inquires, this is a course that is ranked by the students as being above average in relation to other courses taught at ISEP.

\section{DISCUSSION ON THE COURSE EXPERIENCE}

From the author experience (based on discussions with other colleagues teaching similar subjects) hands-on courses on industrial robotics are not frequent due to, mainly, two reasons: the first one is related to the cost of industrial robots that makes difficult to equip laboratories with these devices; the second one relates to the time needed to program, and test the developed programs, online. Since robot programs typically involve the motion of the robot, these programs have to be tested at low velocities for safety reasons in order to avoid collisions that may occur due to unwanted motions of the endeffector. This, in turn, leads to long program developing times. 
In order to overcome these problems faced with traditional courses on robotics, an innovative approach was followed: the practical classes are taught using a commercial off-the-shelf simulation software package for the simulation and off-line programming of industrial robots.

This has proved to be an excellent solution, since the number of enrolled students has been growing along the years and the approval rates have been consistently high. Furthermore, this solution allows students to see the effects of the developed programs in the instant in which they finish them, avoiding the delays in testing the programs in the real robots and avoiding the high costs associated with the robots needed for the practical training.

However, there are now some aspects that deserve an improvement. Due to the increase in the number of students opting for this course, the attendance in practical classes has increased above what was initially expected and that leads to the need for a further robot to allow students test their programs without the bottleneck that is faced presently.

The new robot to be acquired could be from the same brand of the one already available is the laboratory (ABB Robotics). However, in the author opinion, it would be better to acquire a robot from a distinct brand and, in parallel, equip the laboratory with a simulation and off-line programming software from the same brand as the new robot. This would allow offering students with the possibility of developing knowledge and working with robots from two different brands in order to be able to feel the differences in operation and programming that they can face when changing from equipment of one manufacturer to a machine from another different one.

\section{CONCLUSIONS}

This paper presented a course on industrial robots that is currently being offered at ISEP. This course presents as its main objectives to teach the principles of robotic manipulation and its main application fields. The aspects of mathematical foundation of robotics are placed in a second plane, being referred just in an introductory phase of the course. In order to overcome the problems faced with traditional courses on robotics, an innovative approach was followed: the practical classes are taught using simulation software for the simulation and off-line programming of industrial robots.

This has proved to be an excellent solution, since the number of enrolled students has been growing along the years and the approval rates have been consistently high. Furthermore, this solution allows students to see the effects of the developed programs in the instant in which they finish them, avoiding the delays in testing the programs in the real robots and avoiding the high costs associated with the robots needed for the practical training.

\section{ACKNOWLEDGMENTS}

The author thanks all students that have been enrolled in previous editions of the ROBIN course and that contributed to its improvement through several comments and/or suggestions. Special thanks are due to Daniel Basto for developing the first version of the laboratory works instructions scripts that are used along the laboratory classes. Thanks are also due to Rui Carvalho, Cristiano Alves, José Silva and Marco Silva, authors of the simulation models that were used to make the print screens that are used as figures along this text.

\section{REFERENCES}

[1] S. Cherry, "Robots incorporated," IEEE Spectrum, vol. 44, no. 8, pp. 24-29, August 2007.

[2] E. Guizzo, "6.5 million robots now inhabit the earth," http://spectrum.ieee.org/automaton/Rob./Rob.software/world_robot_population_reaches_6_and_half_million, Last acessed on September, 27, 2013.

[3] IFR, "Robot sales in 2011 exceeded all expectations," http://www.ifr.org/news/ifr-press-release/robot-sales-in-2011-exceededall-expectations-361, Last acessed on September, 27, 2013.

[4] M. Copeland and K. Kelleher, "The new new careers," http://money.cnn.com/galleries/2007/biz2/0704/gallery.jobs_new_career s.biz2/2.html, Last acessed on September, 27, 2013.

[5] "The bologna declaration of 19 june 1999, joint declaration of the european ministers of education," http://www.bolognabergen2005.no/Docs/00-

Main_doc/990719BOLOGNA_DECLARATION.PDF, Last acessed on September, 27, 2013.

[6] R. D. Beer, H. J. Chiel, and R. F. Drushel, "Using autonomous robotics to teach science and engineering," Communications of the ACM, vol. 42, no. 6, pp. 85-92, June 1999.

[7] A. Valera, M. Vallés, J. L. Díez, and C. García, "Development of bluetooth communications for lego-based mobile robot laboratories," Proceedings of the 44th IEEE Conference on Decision and Control, and the European Control Conference 2005, Seville, Spain, pp. 3426-3431, December 12-15 2005.

[8] J.-F. Lalonde, C. P. Bartley, and I. Nourbakhsh, "Mobile robot programming in education," Proceedings of the 2006 IEEE International Conference on Robotics and Automation, Orlando, Florida, pp. 345350, May 2006.

[9] S. V. Shamlian, K. Killfoile, R. Kellogg, and F. Duvallet, "Fun with robots: A student-taught undergraduate robotics course," Proceedings of the 2006 IEEE International Conference on Robotics and Automation, Orlando, Florida, pp. 369-374, May 2006.

[10] C.-S. Lee, J.-H. Su, K.-E. Lin, J.-H. Chang, M.-H. Chiu, and G.-H. Lin, "A hands-on laboratory for autonomous mobile robot design courses," Proceedings of the 17th IFAC World Congress, Seoul, Korea, pp. 97439748, July 6-11 2008.

[11] R. Marín, P. J. Sanz, P. Nebot, and R. Esteller, "The internet-based uji tele-lab: System architecture," Proceedings of the 2003 Systems, Man and Cybernetics Conference, pp. 4904-4909, 2003.

[12] C. Cosma, M. Confente, D. Botturi, and P. Fiorini, "Laboratory tools for robotics and automation education," Proceedings of the 2003 IEEE International Conference on Robotics and Automation, Taipei, Taiwan, pp. 3303-3308, September 2003.

[13] H. E. Motuk, A. M. Erkmen, and I. Erkmen, "Student performance evaluation in web based access to robot supported laboratories," Proceedings of the 2003 IEEE International Conference on Robotics and Automation, Taipei, Taiwan, pp. 4408-4413, September 2003.

[14] D. Fabri, C. Falsetti, S. Ramazzotti, and T. Leo, "Robot control designer education on the web," Proceedings of the 2004 IEEE International Conference on Robotics and Automation, New Orleans, LA, USA, pp. 1364-1369, April 2004.

[15] F. Carusi, M. Casini, D. Prattichizzo, and A. Vicino, "Distance learning in robotics and automation by remote control of lego mobile robots," Proceedings of the 2004 IEEE International Conference on Robotics and Automation, New Orleans, LA, USA, pp. 1820-1825, April 2004.

[16] J. Fernández and A. Casals, "Open laboratory for robotics education," Proceedings of the 2004 IEEE International Conference on Robotics and Automation, New Orleans, LA, USA, pp. 1837-1842, April 2004. 
[17] P. R. Coelho, R. F. Sassi, E. Cardozo, E. G. G. aes, L. F. Faina, A. Z. Lima, and R. P. Pinto, "A web lab for mobile robotics education," Proceedings of the 2007 IEEE International Conference on Robotics and Automation, Roma, Italy, pp. 1381-1386, April 2007.

[18] G. T. McKee, "The development of internet-based laboratory environments for teaching robotics and artificial intelligence," Proceedings of the 2002 IEEE International Conference on Robotics and Automation, Washington, DC, USA, pp. 2695-2700, May 2002.

[19] R. Marín, P. J. Sanz, and J. S. Sánchez, "A very high level interface to teleoperate a robot via web including augmented reality," Proceedings of the 2002 IEEE International Conference on Robotics and Automation, Washington, DC, USA, pp. 2725-2730, May 2002.

[20] A. Stothert, R. Shenoy, and M. Carone, "Interactive graphical tools for controller design," Proceedings of the 45th IEEE Conference on Decision and Control, San Diego, CA, USA, pp. 4570-4578, December 13-15 2006.

[21] Y. Lu and B. Hu, "Solving kinematics and active forces of some parallel manipulators by a block diagram modeling system," Proceedings of the ASME 2007 International Design Engineering Technical Conferences and Computers and Information in Engineering Conference, Las Vegas, Nevada, USA, pp. DETC2007-34 448 (in CD-ROM), September 2007.

[22] S. Carpin, M. Lewis, J. Wang, S. Balakirsky, and C. Scrapper, "Usarsim: a robot simulator for research and education," Proceedings of the 2007
IEEE International Conference on Robotics and Automation, Roma, Italy, pp. 1400-1405, April 2007.

[23] C. S. Silva, G. M. Serrador, and L. F. Baptista, "Improving simulation and experimentation in marine engineering education using automation dedicated software," Proceedings of CONTROLO 2006: 7th Portuguese Conference on Automatic Control, Lisbon, Portugal, September 11-13 2006.

[24] K. S. Rawat and G. H. Massiha, "A hands-on laboratory based approach to undergraduate robotics education," Proceedings of the 2004 IEEE International Conference on Robotics and Automation, New Orleans, LA, USA, pp. 1370-1374, April 2004.

[25] H. F. Manesh, M. Bal, and M. Hashemipour, "Draft: Applications of virtual reality in computer integrated manufacturing systems," Proceedings of the ASME 2007 International Design Engineering Technical Conferences and Computers and Information in Engineering Conference, Las Vegas, Nevada, USA, pp. DETC2007-35331 (in CDROM), September 2007.

[26] G. Augusti, "Accreditation of engineering programmes: European perspectives and challenges in a global context," European Journal of Engineering Education, vol. 32, no. 3, pp. 273-283, June 2007 (http://dx.doi.org/10.1080/03043790701276742).

[27] ENAEE, "EUR-ACE® system," http://www.enaee.eu/eur-ace-system, Last acessed on September, 27, 2013. 